\title{
UN INCIDENTE MILITAR EN LA TRANSICIÓN: LA ELECCIÓN DEL GENERAL GABEIRAS COMO JEFE DEL ESTADO MAYOR DEL EJÉRCITO (1979)
}

\section{A MILITARY INCIDENT IN TRANSITION: THE ELECTION OF GENERAL GABEIRAS AS CHIEF OF GENERAL STAFF OF THE ARMY (1979)}

\author{
Roberto Muñoz Bolaños \\ Universidad Francisco de Vitoria / Universidad Camilo José Cela
}

Entregado el 28-9-2013 y aceptado el 5-9-2014.

\begin{abstract}
Resumen: El 17 de 1979, la máxima jerarquía del Ejército español, el Jefe del Estado Mayor del Ejército (JEME), teniente general Tomás Liniers y Pidal, cesaba de su cargo por razones de edad. Para sustituirlo, el vicepresidente del Gobierno para Asuntos de la Seguridad, el teniente general Manuel Gutiérrez Mellado, que ya estaba enfrentado con la cúpula militar desde la legalización del Partido Comunista de España (PCE), y que no confiaba en los principales mandos del Ejército, optó por elegir a un amigo suyo, sin prestigio en el seno de las Fuerzas Armadas (FAS), pero de su completa confianza: el general de división José Gabeiras Montero. La elección de Gabeiras provocó una auténtica conmoción en el Ejército, y aumento aún mas si cabe la desconfianza de los militares hacía el Gobierno de Suárez. Sin embargo, menos de dos años después, durante el golpe de Estado del 23-F, la elección de Gabeiras se demostraría clave para el mantenimiento del sistema democrático, ya que evitó la movilización de buena parte de las capitanías generales ${ }^{1}$ en favor de los golpistas, como era el deseo de sus mandos.
\end{abstract}

${ }^{1}$ En 1981, existían 11 capitanías generales, cuyos mandos - todos tenientes generales - controlaban todas las unidades militares. Eran: 
Palabras clave: Fuerzas Armadas, golpismo militar, Jefe del Estado Mayor del Ejército, reforma militar, transición española.

\begin{abstract}
The May 17, 1979, the highest ranking Spanish Army, the Chief of Staff of the Army (JEME), Lieutenant General Thomas Liniers and Pidal, ceased from office for reasons of age. To replace it, the Deputy Prime Minister for Security Affairs, Lieutenant General Manuel Gutiérrez Mellado, who was faced with military leaders from the legalization of the Communist Party of Spain (PCE), and did not trust the major Army commands, decided to choose a friend, without prestige within the Armed Forces (SAF), but his complete confidence: Major General José Gabeiras Montero. Gabeiras Choosing caused a commotion in the Army, and even more if possible increase the distrust of the military was the Suarez government. However, less than two years later, during the coup of 23-F, the choice of Gabeiras would prove key to the maintenance of the democratic system, and that prevented the mobilization of much of the military commands in favor of the coup, as was the wish of their commanders.
\end{abstract}

Key words: Armed Forces, military coups, Chief of Staff of the Army, military reform, Spanish transition.

I Región Militar (Madrid): Madrid, Ávila, Cáceres, Ciudad Real, Cuenca, Guadalajara y Toledo.

II Región Militar (Sevilla): Sevilla, Badajoz, Cádiz, Córdoba, Huelva y Ceuta. Murcia.

III Región Militar (Valencia): Valencia, Albacete, Alicante, Castellón de la Plana y

IV Región Militar (Barcelona): Barcelona, Gerona, Lérida y Tarragona.

V Región Militar (Zaragoza): Huesca, Teruel, Zaragoza y Soria.

VI Región Militar (Burgos): Burgos, Logroño, Navarra, Santander, Alava, Guipúzcoa y Vizcaya.

VII Región Militar (Valladolid): Valladolid, Asturias, León, Salamanca, Zamora, Palencia, Segovia y Valladolid.

VIII Región Militar (La Coruña): La Coruña, Lugo, Orense y Pontevedra.

IX Región Militar (Granada): Almería, Granada, Jaén, Málaga y Melilla.

Capitanía General de las Baleares (Palma de Mallorca).

Capitanía General de las Canarias (Santa Cruz de Tenerife). 


\section{Las FAS y el proceso de transición a la democracia}

Las FAS eran, a la muerte del general Franco el 20 de noviembre de 1975, el principal sostén del régimen. Sus miembros, muchos de los cuales habían participado en el bando vencedor durante la guerra civil, consideraban al régimen nacido el 18 de julio de 1936, como propio, y a su fundador, como su caudillo y jefe supremo efectivo. Sin embargo, estas FAS, educadas en el culto al general Franco y en la devoción por su régimen, y que tenían en su mentalidad todos los componentes característicos de unos ejércitos intervencionistas en política ${ }^{2}$, no eran inicialmente contrarias, en su inmensa mayoría, a una reforma del régimen político vigente, siempre que esta se hiciera desde el respeto a la legalidad franquista y tutelada de alguna manera por la cúpula militar ${ }^{3}$. Sin embargo, los cambios políticos operados entre 1975 y 1978, unidos a la crisis económica de los años $70^{4}$, y sobre todo, a la oleada terrorista protagonizada por Euzkadi Ta Askatasuna (ETA) y los Grupos de Resistencia Antifascista Primero de Octubre $(\mathrm{GRAPO})^{5}$ - junto con el aumento del sentimiento separatista, especial-

${ }^{2}$ Roberto Muñoz Bolaños, «Operación Galaxia», Historia del Tiempo Presente, 20, 2012, pp. 119-125.

3 Este planteamiento se basaba en que el artículo 37 de la Ley Orgánica del Estado, establecía que «Las Fuerzas Armadas de la Nación, constituidas por los Ejércitos de Tierra, Mar y Aire y las Fuerzas de Orden Público, garantizan la unidad e independencia de la Patria, la integridad de sus territorios, la seguridad nacional y la defensa del orden institucional» (Boletín Oficial del Estado, 1 de enero de 1967); lo que justificaba que las FAS tutelasen cualquier cambio político, como así reconocía el almirante Gabriel Pita da Veiga, que refiriéndose a este artículo, afirmaba: «no las interponen [a las FAS] como barrera frente a toda reforma, sino que depositan en ellas la garantía extrema de que el natural perfeccionamiento y la necesaria adaptación de las normas gobernados y se alcancen por los cauces que las propias leyes establecen». «Las Fuerzas Armadas, garantía extrema de que la reforma responda al sentir de los gobernados», El País, 11 de mayo de 1976 , p. 9.

4 Como consecuencia de las dos crisis del petróleo (1973 y 1979), el número de desempleados paso de 256.600 en 1975 a 1.566 .200 en 1981 , y la inflación del $14,1 \%$ en 1975 al 14,4\% en 1981, siendo su momento culminante el año 1977 cuando alcanzó el 26,4\%. Albert Carreras y Xavier Tafunell (coord.), Estadísticas históricas de España. Siglos XIX y XX, Fundación BBVA, Bilbao, 2005, vol. I, p. 1218.

${ }_{5}$ Los muertos provocados por el GRAPO fueron 84 entre 1975 y 1982, y los de ETA, 345; siendo los años 1979 y 1980, con 107 y 98 muertos, el punto culminante de esta escalada. Horacio Roldán Barbero, Los GRAPO. Un estudio criminológico, Comares, Madrid, 2008, pp. 82-90. Pablo Gutiérrez, Todas las víctimas de ETA, http://www.elmundo.es/eta/ victimas/ 
mente en el País Vasco ${ }^{6}-$, hicieron que esta actitud cambiara; produciéndose un aumento progresivo del intervencionismo militar. En este proceso, pudieron distinguirse tres fases, de acuerdo con la tipología establecida por el politólogo e historiador estadounidense Samuel E. Finer ${ }^{7}$.

La primera fue la de Influencia ${ }^{8}$. Cronológicamente abarcó la presidencia de Carlos Arias Navarro (XI/1975-VI/1976), cuyo Gobierno careció de un proyecto articulado para iniciar la transición a la democracia. En esta situación de impasse, los sectores más involucionistas del franquismo - políticos y castrenses - utilizaron a los militares que formaban parte del Gobierno como correa de transmisión de su deseo, que no era otro que el mantenimiento integro del Estado del 18 de julio. Las figuras claves sobre las que actuaron fueron el entonces vicepresidente del Gobierno para Asuntos de la Defensa, el teniente general Fernando de Santiago y Díaz de Mendivil, y en menor medida, el ministro del Ejército, el teniente general Félix Álvarez-Arenas y Pacheco. Entre las entrevistas que sostuvieron con ese propósito, destacaron tres. La primera fue con José Antonio Girón de Velasco, líder de la línea falangista y no monárquica del franquismo - azul-, y el teniente general en situación B, Carlos Iniesta Cano, su correligionario militar, el 12 de enero de $1975^{9}$. La segunda, con

${ }^{6}$ La radicalización del nacionalismo periférico, especialmente el vasco, tuvo su manifestación en dos hechos de gran impacto en la opinión pública. El primero fue la visita del presidente del Gobierno, Adolfo Suárez, que no recibió los honores correspondientes a su cargo. Lo que provocó un fuerte impacto en la prensa. Véase «Crítica acogida», Diario 16, 10 de diciembre de 1980, p. 1; «Frialdad oficial y protesta», El País, 10 de diciembre de 1980, p. 1; «Fría acogida», Ya, 10 de diciembre de 1980, p. 1, y «España maltratada en su presidente del Gobierno», El Alcázar, 10 de diciembre de 1980, p. 1. Fuerza Nueva, la revista de extrema derecha, la más leída en los cuarteles, calificaba la actitud de Suárez de «ridícula». Fuerza Nueva, 20 de diciembre de 1980, pp. 5-7. El segundo, la visita del rey Juan Carlos I, que provocó un grave incidente en la Casa de Juntas de Guernica (Vizcaya); muy comentado por la prensa de extrema derecha. Véase « Chantaje del PNV al Gobierno y al Estado», El Alcázar, 5 de febrero de 1981, p. 1. «Editorial», El Heraldo Español, 1319 de febrero de 1981, p. 3.

7 Samuel E. Finer, Los militares en la política mundial, Editorial Sudamericana, Buenos Aires, 1969.

${ }^{8}$ La Influencia es una forma de intervención militar propia de países con una cultura política desarrollada. Consiste en que las FAS tratan de influir en el Gobierno siguiendo los cauces legales normales, con objeto de atraerlos a su propia forma de pensar, pudiendo incluso llegar a la rivalizar con las autoridades civiles, y discutir con ellas, pero sin pasar nunca los limites de la legalidad. Ibid, p. 187.

9 Carlos Fernández, Los militares en la transición política, Argos Vergara, Barcelona, 1982, p 63. 
el tecnócrata Laureano López Rodó, el 15 de enero de $1975^{10}$. Y la tercera, con el teniente general Alfonso Pérez Viñeta, otro azul; el teniente general Iniesta Cano; el general de división Tomás Liniers y Pidal, comandante general de Melilla, y el general de brigada de Infantería Juan Cano Portal, el 8 de marzo de 1976. Durante la misma, se elaboró un documento donde se plasmaban las inquietudes del Ejército en material política, que fue entregado al Rey por De Santiago. El Jefe del Estado, tras leerlo, recomendó al militar que se atuviera a sus competencias, y no se entrometiese en las del presidente del Gobierno ${ }^{11}$.

La segunda fue la de Extorsión ${ }^{12}$. Cronológicamente se correspondió con la presidencia de Adolfo Suárez entre el 3 de julio de 1976 - nombramiento del político abulense como jefe del ejecutivo- y el 9 de abril de 1977 - legalización del Partido Comunista de España (PCE) - . Este periodo estuvo caracterizado porque el nuevo Gobierno si definió un proyecto político, que conllevaba el establecimiento de un régimen democrático. Ante esta tesitura, determinados sectores involucionistas, tanto políticos como militares, decidieron intervenir para detener este proceso, dimitiendo o amenazando con una intervención militar, pero sin que esta actuación tuviera carácter institucional, es decir, sin que fuera consensuada por toda la cúpula militar. Esta extorsión se manifestó en tres acontecimientos. El primero fue la reunión entre el jefe del ejecutivo y los consejos superiores de los tres Ejércitos ${ }^{13}$ el 8 de septiembre de 1976;

${ }^{10}$ Laureano López Rodó, Memorias IV. Las claves de la Transición, Planeta, Barcelona, 1993, p. 212

11 Javier Tusell, Tiempo de incertidumbre. Carlos Arias Navarro entre el Franquismo y la Transición (1973-1976), Crítica, Barcelona, 2003, pp. 279-281.

${ }^{12}$ La extorsión o blackmail es una forma de intervención militar propia de países de menor cultura política. Esta forma de intervención implica la amenaza de no colaborar con las autoridades civiles, la desobediencia directa, la intimidación e incluso la amenaza de violencia contra el Gobierno, sino sigue los dictados de las FAS. Samuel E. Finer, op. cit., pp. 187-201.

${ }^{13}$ Los consejos superiores del Ejército de Tierra, el Ejército del Aire y la Armada estaban integrados por todos los tenientes generales con mando. En el caso del primero, lo formaban el ministro, mientras existió ese cargo; el Jefe del Estado Mayor Central (EMC), luego llamado JEME; los capitanes generales de las 11 regiones militares - las nueve peninsulares, más Canarias y Baleares-, el jefe del Centro Superior de Estudios de la Defensa (CESEDEN), el jefe de la Escuela Superior del Ejército (ESE), el director general de la Guardia Civil, el presidente del Consejo Supremo de Justicia Militar (CSJM), y todos los ex JEME que no estuvieran en la reserva (menores de 70 años). Actuaba como un órgano colegiado, y elaboraba ternas para el ascenso a los diferentes empleos del generalato y para cubrir los principales mandos del Ejército. Su capacidad de influencia fue disminu- 
el segundo, la dimisión del teniente De Santiago, el 21 de septiembre de 1976, y el tercero, la legalización del PCE, el 9 de abril de $1977^{14}$. En los tres casos, la acción desarrollada por determinados mandos militares fracasó completamente, ya que careció del apoyo mayoritario de la cúpula de las FAS, imposibilitando así que los Ejércitos pudiesen controlar el proceso de cambio político por vías «legales».

La tercera etapa fue la de Desplazamiento ${ }^{15}$ y Suplantación $^{16}$, que se desarrolló entre abril de 1977 y el 27 de octubre de 1982, y estuvo marcada porque los sectores más intervencionistas del las FAS, ante el fracaso de las acciones anteriores de Influencia y Extorsión, optaron por poner en marcha operaciones golpistas, ya fuesen de Desplazamiento o de Suplantación. Estas acciones fueron cuatro: la operación Galaxia $(1978)^{17}$, la intentona Torres Rojas (1979) ${ }^{18}$, el golpe de Estado del 23-F (1981) ${ }^{19}$ y la operación Cervantes (1982) ${ }^{20}$.

Fue durante esta tercera etapa cuando se produjo la elección del general de división José Gabeiras Montero como Jefe del Estado Mayor del Ejército (JEME).

yendo a medida que el control de las FAS paso al poder civil. Véase Roberto Muñoz Bolaños, «"A por los golpistas”. El fin de la involución militar y el control de las fuerzas Armadas durante el primer Gobierno socialista (1982-1986)» en Álvaro Soto Carmona y Abdón Mateos, Historia de la época socialista . España, 1982-1996, UAM-UNED, Madrid, 2011, pp. 9-10.

14 Roberto Muñoz Bolaños, «Movimientos involucionistas y tramas golpistas», en Fernando Puell de la Villa y Sonia Ángel Santano (eds.), El legado del general Gutiérrez Mellado, IUGM, Madrid, 2013, pp. 169-188.

15 El desplazamiento es una forma de intervención militar propia de países con baja cultura política. Consiste en la sustitución de un Gobierno civil por otro, gracias a la acción de las FAS. Este desplazamiento se puede realizar de tres formas: La amenaza de una intervención militar; la negativa de las FAS a defender al Gobierno frente al desorden civil, y la violencia militar. Esta última cobra tres formas: el ataque directo por parte de las FAS al Ejecutivo (golpe de Estado), o la rebelión sucesiva de las guarniciones militares (cuartelazo o pronunciamiento). Samuel E. Finer, op. cit., pp. 201-216.

${ }^{16}$ La suplantación es una forma de intervención militar también propia de países de baja cultura política. Consiste en sustituir el Gobierno civil por un Gobierno militar, y se desarrolla de acuerdo a las mismas formas que el desplazamiento. Ibid, p. 201.

17 Roberto Muñoz Bolaños, «Operación Galaxia», pp. 128-182.

18 Roberto Muñoz Bolaños, «El general Torres Rojas en la división acorazada Brunete: el involucionismo militar ante la transición democrática, 1975-1980», Vínculos de Historia, 3, 2014, pp. 343-369.

19 Roberto Muñoz Bolaños, «Movimientos involucionistas y tramas golpistas», pp. 199-214

${ }^{20}$ Ibid., pp. 214-215. 


\section{La jefatura del Estado Mayor del Ejército JEME. La reforma militar de Gutiérrez Mellado}

La aparición del cargo de JEME en la estructura militar española no puede desvincularse de uno de los episodios más trascendentes de la Transición: la reforma militar, realizada por el capitán general honorario Manuel Gutiérrez Mellado, como vicepresidente del Gobierno para Asuntos de la Defensa entre el 23 de septiembre de 1976 y el 26 de febrero de 1981. Este proceso tuvo dos ámbitos de desarrollo básicos: El primero fue la creación de un nuevo organigrama institucional que supuso la modernización, pero también la subordinación de las FAS al poder civil. El segundo, la aplicación de una nueva política de ascensos donde los criterios objetivos - antigüedad y Hoja de Servicios - sobre los que se apoyaba la legislación vigente ${ }^{21}$, pasarían a un segundo plano frente a otros subjetivos - lealtad a la política reformista del Gobierno-, lo que trajo como consecuencia que el alto mando de las FAS, especialmente el del Ejército, perdiera su unidad corporativa. Esta política de ascensos alcanzaría precisamente su punto culminante con la elección del general Gabeiras como JEME.

Respecto al primero de los ámbitos citados, Gutiérrez Mellado, un militar con un gran prestigio en el seno de las FAS al inicio de la Transición $^{22}$, heredó la anquilosada estructura militar del franquismo, basada

${ }^{21}$ La Ley 12/1961, de 19 de abril, sobre declaración de aptitud para el ascenso y ascensos en régimen ordinario de los Oficiales Generales y particulares en el Grupo de Mando de Armas y sus asimilados de la escala activa del Ejército de Tierra (BOE, 22 de abril de 1961), puntualmente modificada por la Ley 15/1973, de 19 de diciembre (BOE, 20 de diciembre de 1973), y vigente en ese momento, establecía, en su art. 3: «Serán condiciones indispensables para obtener la declaración de aptitud para el ascenso en los distintos empleos las siguientes: Primera. Estar bien conceptuado en la hoja de servicios. Segunda. Haber cumplido el tiempo mínimo de efectividad, de destino y de mando que para cada empleo se determina en el artículo quinto de la presente Ley. Tercera. Haber superado las pruebas de aptitud que convenga exigir para garantizar una adecuada utilización de los medios y procedimientos propios de cada empleo, surgidos como consecuencia de la evolución de la técnica militar». Esta Ley quedará definitivamente derogada por la Ley 48/1981, de 24 de diciembre, de clasificación de mandos y regulación de ascensos en régimen ordinario para los militares de carrera del Ejército de Tierra. BOE, 11 de enero de 1982 .

22 Este prestigio fue reconocido por militares contrarios a Gutiérrez Mellado desde el punto de vista ideológico como el coronel de Artillería Diplomado de estado Mayor (DEM) José Ignacio San Martín López, condenado por el golpe de Estado del 23-F o el 
en tres ministerios militares - uno para cada uno de los Ejércitos: Armada, Ejército de Tierra y Ejército del Aire, que siempre estuvieron encabezados por militares de carrera - y un organismo coordinador absolutamente inoperante: el Alto Estado Mayor (AEM) ${ }^{23}$. Una estructura, y esto era lo verdaderamente importante, donde el poder militar constituía un ente autónomo, directamente dependiente del general Franco. Esta estructura ya había intentado ser modificada por el mentor de Gutiérrez Mellado, el teniente general Manuel Díaz-Alegría - entonces Jefe del AEM - , en 1971 con la llamada Ley Orgánica de la Defensa Nacional, que nunca entró en vigor ${ }^{24}$. Sin embargo, Gutiérrez Mellado no olvidó nunca ese proyecto - que él había ayudado a redactar-, y decidió ponerlo en vigor cuando pasó a formar parte del Gobierno. El objetivo que se perseguía era doble: por un lado, mejorar el funcionamiento de las FAS, mediante la unificación de los tres ministerios en uno sólo y la coordinación operativa de los tres Ejércitos, y por otro, subordinar los Ejércitos al poder civil ${ }^{25}$.

El primer paso se dio el 23 de diciembre de 1976, cuando se aprobó el Real Decreto 3026/1976. Esta norma creaba el cargo de JEME - sustituyendo al tradicional de Jefe del Estado Mayor Central (EMC) - y establecía que era «la primera autoridad de la cadena de mando militar del Ejército de Tierra bajo la dependencia política del ministro ${ }^{26}$, pasando a desempeñar la jefatura operativa del mismo; mientras que el ministro del Ejército quedaba reducido a funciones administrativas. El 8 de febrero de

teniente general Jesús González del Yerro. José Ignacio San Martín, Servicio Especial. A las órdenes de Carrero Blanco. De Castellana a El Aaiún, Planeta, Planeta, 1983, pp. 224-225. Archivo Personal del Autor (APA). Testimonio oral del teniente general Jesús González del Yerro Fernández. Madrid, 21 de marzo de 1996. Testimonio oral del general de División Luis Torres Rojas. Madrid, 4 de junio de 1998. El teniente general Villaescusa, compañero de promoción y amigo de Gutiérrez Mellado desde los tiempos de la AGM, afirma, acerca de su labor: «Creo que quería obrar bien, aunque a veces se equivocaba... el citado general era muy listo y obraba siempre de buena fe». APA. Testimonio escrito del teniente general Emilio Villaescusa Quilis. Madrid, 20 de noviembre de 1998.

23 Roberto Muñoz Bolaños, «La institución militar en la posguerra (1939-1945)» en Fernando Puell de la Villa y Sonia Alda Mejías (eds.), Los ejércitos del franquismo (1939-1975), IUGM, Madrid, pp. 18-22.

${ }^{24}$ BOE, 11 de enero de 1967. Fernando Puell de la Villa, Gutiérrez Mellado. Un militar del siglo XX (1912-1995), Biblioteca Nueva, Madrid, 1997, pp. 165-166.

25 Ibid, pp. 205-206.

${ }^{26}$ BOE, 11 de enero de 1977. 
1977, se aprobó el Real Decreto 9/1977, que establecía las mismas competencias para el Jefe del Estado Mayor del Ejército del Aire (JEMA) ${ }^{27}$. En el caso de la Armada, el Almirante Jefe del Estado Mayor de la Armada (AJEMA), ya era el jefe operativo de este Ejército por el Decreto 2888/1970, del 12 de septiembre. Por tanto, la figura del JEME, como la del JEMA, y antes la del AJEMA cobraban una importancia trascendental, ya que eran los jefes efectivos de los tres Ejércitos; pero no suponían realmente ningún cambio en las relaciones entre FAS y Gobierno; pues, los jefes de EM, dependían políticamente de sus ministros que seguían siendo militares.

El paso siguiente se produjo el 8 de febrero de 1977, cuando se aprobó el Real Decreto-Ley $11 / 1977^{28}$, por el que se creaba la Junta de Jefes del Estado Mayor (JUJEM), que se definía como el órgano colegiado superior de la cadena de mando militar y de asesoramiento técnico en la elaboración de la política militar. Este órgano estaba integrado inicialmente por el Jefe del AEM como presidente, y el JEME, el AJEMA y JEMA. Posteriormente, el AEM desaparecería, y la presidencia de la JUJEM pasaría al Presidente de la Junta de Jefes de Estado Mayor (PREJUJEM) ${ }^{29}$.

La creación de la JUJEM constituyó la base para la unificación operativa de los tres Ejércitos. Pero se hacía necesario que esa unificación también se manifestara en el ámbito político-administrativo. Así, por el Real-Decreto 1558/77, de 4 de julio ${ }^{30}$, desaparecieron los tres ministerios militares, que fueron sustituidos por el Ministerio de Defensa. Su primer titular sería un militar, el propio Gutiérrez Mellado, pero esta decisión constituía el primer paso en el proceso de subordinación de las FAS al Gobierno. De hecho, esta norma jurídica afirmaba que el nuevo departamento nacía como órgano «encargado de la ordenación y coordinación de la política general del Gobierno en cuanto se refiere a la Defensa Nacional, así como de la ejecución de la política militar correspondiente». Para

27 Fernando Puell de la Villa, op. cit., pp. 205-206.

28 BOE, 11 de febrero de 1977.

${ }^{29}$ El artículo 38 de la LOE hacía referencia al AEM, y dado su carácter de Ley Fundamental no podía modificarse sino era mediante una reforma. Por eso, el AEM siguió existiendo hasta la Ley 26/1980, de 19 de mayo, por la que se suprime el Alto Estado Mayor, una vez transferidas las funciones a la Junta de Jefes de Estado Mayor y Altos Organismos de Defensa. El Presidente de la Junta de Jefes de Estado Mayor (PREJUEM) asumía las funciones del Jefe del AEM. BOE, 13 de junio de 1980.

${ }^{30}$ BOE, 7 de julio de 1977. 
realizar esa coordinación, se establecía la creación de la Subsecretaria de Defensa, ejercida por «un Oficial General o Almirante en situación de actividad», de la que dependían tres Secretarias Generales - una para cada Ejército-.

Los militares pensaron entonces que el Ministerio de Defensa - que siempre estaría en manos de un oficial general de alguno de los tres Ejércitos - se encargaría únicamente de la gestión, mientras que el mando efectivo y operativo de las FAS quedaría en manos del Rey como capitán general de los tres Ejércitos. De hecho, la defensa de la jefatura Real de las FAS fue la última trinchera que intentaron defender, tras su fracaso en el intento tutelar el proceso de cambio político. La justificación que dieron para abanderar esa postura fue que se trataba de la única manera de mantener un ejército auténticamente profesional y apolítico, lo que no ocurriría si el mando militar estaba en manos de un político. En su defensa fue especialmente vehemente el primer JEME, el teniente general José Miguel Vega Rodríguez ${ }^{31}$, al que Gutiérrez Mellado calificaba como «un amigo»; pero que ya estaba enfrentado con el vicepresidente del Gobierno por su política de ascensos. La culminación de este enfrentamiento se produciría tras la aprobación del Real Decreto 836/1978, de 27 de marzo de $1978^{32}$, por el que la JUJEM pasaba a depender del presidente del Gobierno, a través del ministro de Defensa, convirtiendo la jefatura Real de las FAS en algo meramente simbólico. Esta decisión, que se adecuaba al proyecto de Gutiérrez Mellado de subordinar las FAS al poder civil, provocó una auténtica conmoción en el

31 El teniente general José Miguel Vega Rodríguez fue uno de los militares más interesantes de la Transición. Nacido el 19 de diciembre de 1913 en Ceuta, y perteneciente a una vieja familia militar, tuvo una brillante carrera, destacando su actuación en la Guerra Civil y en la División Azul, llegando a ganar un ascenso por méritos de guerra. Sin embargo, a pesar de ese pasado que le podría vincular ideológicamente con el franquismo más puro, Vega siempre fue considerado un militar liberal, aunque él se definía como «socialdemócrata». Véase María Mérida, Mis conversaciones con los generales, Plaza \& Janés, Barcelona, 1979, p. 269. Ese carácter «liberal» e incluso «socialdemócrata» se manifestaría en su discurso de la Pascual Militar de 1978, donde afirmó: «...incluso en el bando opuesto a nosotros se han destacado personas que, a lo mejor, si hubieran sentido la vocación a edad temprana, hubieran sido unos magníficos generales y quizá no hubieran pensado de la manera que pensaban, y me estoy refiriendo a Modesto, a Lister, etc., que indiscutiblemente tenían algunas de estas virtudes militares que a todos nos interesa tener, sobre todo en los más altos escalafones». «Los militares deben cumplir sin reservas mentales, las órdenes de sus superiores», $A B C, 19$ de mayo de 1978, p. 9.

32 BOE, 29 de mayo de 1978 
seno de las FAS; lo que unido al aumento de la escalada terrorista y a la forma en que se había legalizado el PCE, contribuyó aun más si cabe a desprestigiar la figura de Gutiérrez Mellado ${ }^{33}$. Por su parte, Vega, que no había conseguido su objetivo de crear unas FAS «apolíticas» dimi-

33 En 1978, el prestigio de Gutiérrez Mellado había disminuido enormemente en el seno de las FAS. Un ejemplo de lo que decimos se puede leer en la siguiente hoja clandestina distribuida en los cuarteles por la Unión Patriótica Militar (UPM), una organización clandestina, que quería rememorar a la vieja Unión Militar Española (UME). Dice así: «A D. Andrés González de Suso y Fernández Matauco, D. Gonzalo González Gullón, D. Manuel Álvarez Gullón, D. Manuel Álvarez Campana Molina, D. Ángel de Lossada y Aymerich y D. José Montojo y González Trevilla. Los artilleros que estáis alrededor del Guti y que le ayudáis en su sorda, sucia y cobarde labor de acabar a traición con España, por resentimiento suyo contra Franco y concomitancias económicas con los políticos, merecéis el desprecio del Arma. Franco sabía que durante la guerra fue un espía de los dos bandos hasta que casi finalizada se quedó en el que se veía vencedor. Y así le trató aunque lo dejó en activo. Hoy os utiliza contra el Ejército. Su moral militar esta vista cuando pone en libertad a Boadella y niega a Tejero lo que siempre concedieron hasta al Lute para sus exámenes. Y cuando retira o deja retirar la fuerza pública cuando se ofende a España, y manda que carguen contra quienes la aclaman, vitorean y honran su Bandera. Sabemos todos que por las pocas pesetas que os da, compra vuestra conciencia y hasta sois sus cómplices. Son ya demasiados asesinatos, huelgas, ruina económica, separatismos, ultrajes a la Bandera, desaparición de ésta del territorio vasco, insultos al Ejército, asaltos a los cuarteles, etc., para que sigáis impasibles sin hacerle llegar el clamor de todos. Hay Regimientos en que la entrada de de un Oficial en Estandartes se anuncia con la voz: «Guuuuu...ti» a la que, sin darle importancia, contestan los de dentro: «Hijopuuuuu...ta», como la cosa más natural. Y fingen ignorarlo los coroneles, ya de la General. Si antes del 10 de octubre no abandonáis todos los puestos que ocupáis a su lado, enviaré copia de esta carta a todos los Generales del Arma y al más antiguo de cada empleo de cada Regimiento, Maestranza, Jefatura, Academia, Parque, etc., para que nadie del Arma deje de conoceros. Estad seguro de que cuando acabe esto, que alguna vez acabará, puede esperaros a algunos el Tribunal de Honor e incluso Consejo de Guerra, pero ya sin uniforme. Montojo [Era un Ayudante de S.M. el Rey]: Informa a tu Jefe y mira lo que debe a la influencia de su padre. Seguid diciendo serenidad: pretendéis que los militares nos hagamos los sordos infinitamente sin hacer nada para impedirlo. APA. Documento cedido por el coronel de Infantería Fernando Puell de la Villa. Este desprestigio llego a afectar enormemente a Gutiérrez Mellado, hasta el extremo de que Puell de la Villa, biógrafo del teniente general y siempre bien predispuesto hacia su persona, no duda en afirmar: «Cuantos le habían conocido en etapas anteriores, quedaban sorprendidos al observar la crispación que se apoderaba del vicepresidente si se le ponían objeciones, o se disentía de su forma de enfocar determinados asuntos. Un hombre que se había caracterizado, a lo largo de su carrera, por aceptar e incluso favorecer actitudes críticas en sus subordinados, se transformó en un ser desconfiado, quisquilloso, casi violento en ocasiones; relajado y abierto únicamente en los círculos más íntimos». Fernando Puell de la Villa, op. cit., p. 201. 
tió entonces de forma irrevocable el 17 de mayo de $1978^{34}$, declarando ese mismo día a la periodista de $A B C$, María Mérida: «creo que está disminuyendo la consideración y el prestigio que las Fuerzas Armadas merecen» ${ }^{35}$. Gutiérrez Mellado siempre dijo que Vega dimitió no porque estuviera enfrentado con él por el problema de la jefatura de las FAS, sino porque «quería su puesto, y no lo consiguió» ${ }^{36}$.

La dimisión de Vega obligó a Gutiérrez Mellado a buscarle un sustituto; algo harto complicado ya que la cúpula de las FAS estaba enfrentada con el Gobierno y mayoritariamente en contra del proceso de democratización. Por eso, Gutiérrez Mellado optó por nombrar como JEME a un compañero de su promoción en la Academia General Militar (AGM), por tanto, a otro «cadete de Franco» ${ }^{37}$. Resulta curiosa la elección, ya que Liniers había estado implicado en un intento de Influencia, ya citado, en los tiempos de la presidencia de Carlos Arias Navarro. Pero, a pesar de esto, Gutiérrez Mellado lo eligió porque era «un amigo del Rey», como así lo indicaba un documento fechado en 1975 que había sido entregado a don Juan, y en el que se podía leer sobre él ${ }^{38}$ :

Inteligente; bien preparado militarmente; de tendencia monárquica, pero en la misma postura política que el anterior [se refiere a Gutiérrez Mellado - «después de Franco, las instituciones»-]. No tomo parte en la Guerra Civil. Prestigio entre los que le conocen. Procede de la Academia General de Franco.

34 «Vega Rodríguez juzgaba excesivo el protagonismo del Ministerio de Defensa». El País, 18 de mayo de 1978, p. 11.

35 María Mérida, op. cit., P. 265. La tesis que presentamos es la que más se ajusta a la realidad de los hechos. No obstante, Fernández López considera que la dimisión de Vega se produjo por razones personales, ya que ambos eran militares de mucha personalidad, incapaces de trabajar juntos. Javier Fernández López, El Rey y otros militares. Los militares en el cambio de régimen político en España (1969-1982), Trotta, Madrid, 1998, pp. 123-124.

${ }^{36}$ Fundación Ortega-Marañón. Madrid. Entrevista al capitán general honorario Manuel Gutiérrez Mellado. 8 de septiembre de 1987.

37 Se llamaban «cadetes de Franco» a los militares que se formaron en la Academia General Militar (AGM) de Zaragoza, entre 1928 y 1931, cuando esta fue dirigida por el entonces general de brigada de Infantería Francisco franco Bahamonde. Véase Carlos Blanco Escolar, La Academia General Militar (1929-1931), Labor, Barcelona, 1989. El teniente general Tomás Liniers y Pidal ingresó en la AGM, el 16 de septiembre de 1929. Instituto de Historia y Cultura Militar (IHCM). Anuario Militar Español. Año 1934.

38 Fundación Universitaria Española. Archivo Sainz Rodríguez. La situación de las Fuerzas Armadas en 1975. 
Tal vez pensaba que esa amistad Real le haría favorable al proceso de cambio político que el Jefe del Estado apoyaba. Sin embargo, Gutiérrez Mellado se equivocó. Así, durante un viaje a Argentina, Liniers no sólo condecoró al general Jorge Videla, presidente de la Junta Militar que ejercía la dictadura en aquel país, sino que afirmó ${ }^{39}$ :

Bien tranquila puede estar Argentina de la legitimidad de su empresa. Argentina y España sufren hoy los ataques más aviesos del materialismo ateo y cuando ante esta situación hemos debido emplear la fuerza, nos han criticado por el empleo de la violencia, sin darse cuenta de que la legitimidad del empleo de la fuerza sólo la historia puede juzgarla.

Estas declaraciones, en condiciones políticas normales, hubieran provocado el cese fulminante del teniente general Liniers. Sin embargo, en el verano de 1978, el Gobierno no podía tomar esa decisión pues carecía de hombres de confianza dentro de la cúpula militar; por lo que el sustituto de Liniers podría ser aún más refractario al proceso de cambio político que éste. Además, el proceso de subordinación de las FAS al poder civil no había culminado todavía, y el cese del entonces JEME podría provocar nuevas tensiones. Por eso, Gutiérrez Mellado decidió mantener a Liniers en su cargo hasta el 17 de mayo de 1979, cuando cumplía los 66 años y pasaba a Situación B, lo que permitiría sustituirlo de forma legal. Mientras tanto, Suárez y su vicepresidente continuaron con la reforma militar. Un paso más en este sentido se daría tras las elecciones legislativas del 1 de marzo de 1979. En el nuevo Gobierno de Suárez, que comenzó a ejercer sus funciones el 6 de abril, volvía a aparecer Gutiérrez Mellado como vicepresidente primero del Gobierno para Asuntos de Seguridad, pero la cartera de Defensa pasaba al notario abulense Agustín Rodríguez Sahagún ${ }^{40}$. Por primera vez desde 1939 , un civil pasaba a tener el mando de los Ejércitos. El proceso de subordinación de las FAS al poder político continuaba imparable, aunque no culminaría hasta la primera legislatura de Felipe González (1982-1986) ${ }^{41}$.

39 «Múgica resta importancia a las declaraciones del teniente general De Liniers en Argentina». El País, 19 de julio de 1978, p. 13.

40 ABC, 7 de abril de 1979, p. 5.

41 Roberto Muñoz Bolaños, «"A por los golpistas”. El fin de la involución militar y el control de las Fuerzas Armadas durante el primer Gobierno socialista (1982-1986)», pp. 9-10. 


\section{Los candidatos para sustituir a Liniers}

Un mes después del nombramiento de Rodríguez Sahagún, comenzaron a aparecer quinielas sobre quien podría ser el sustituto de Liniers. Así, el 7 de mayo, el rotativo Diario 16, siempre interesado y muy bien informado de todos los asuntos vinculados con las FAS, dadas sus excelentes relaciones con los antiguos miembros de la Unión Militar Democrática (UMD), publicaba una noticia con los posibles candidatos para el puesto de $\mathrm{JEME}^{42}$ :

También cabe eliminar por la carencia de antecedentes en los últimos años un general de División que suena mucho en los medios castrenses. Se trata del general Gabeiras, actual secretario general de Política de Defensa que además tendría que «saltar» a cuatro o cinco compañeros más antiguos. (...)

El teniente general Milans del Bosch no necesita presentación. Goza de indudable prestigio como jefe nato de tropas, y se le atribuye una gran firmeza monárquica. Quizá desde un punto de vista político se hubiese agradecido una mayor energía en el caso del general Atarés en la base de Cartagena. Al parecer habría rehusado la Capitanía General de Madrid, pensando precisamente en este cargo de Jefe del Estado Mayor.

También el teniente general Jesús González del Yerro sonó más de una vez como sucesor de Liniers. Su anterior puesto de $2 .^{\circ}$ Jefe del Estado Mayor se consideró como una promoción para el mismo. La Capitanía General de Canarias, su actual puesto, tiene la singularidad de ser el único mando unificado de los tres Ejércitos para lo que cuenta con un EMACON (Estado Mayor Conjunto).

La información contenida en esta noticia era completamente veraz, ya que incluía a los dos candidatos preferidos en los ambientes castrenses, y al que era ya el «elegido» por el Gobierno, aunque Diario 16, negaba esta posibilidad. Se trataba en todo caso, de tres candidatos muy distintos.

El primero, Jaime Milans del Bosch y Ussía, pertenecía a la aristocracia militar española y estaba emparentado con la gran burguesía industrial vasca. Nacido en Madrid, el 8 de junio de 1915, ingresó como soldado ${ }^{43}$ en el Ejército en 1934, participando en la represión de la revolución as-

42 Diario 16, 7 de mayo de 1979, p. 2. El subrayado es nuestro.

43 La legislación militar aprobada por Manuel Azaña, ministro de la Guerra, en 1931 obligaba a los futuros oficiales a permanecer durante un año como soldados voluntarios. 
turiana de ese mismo año. Poco después, el 28 de diciembre de 1934, ingresa en la Sección de Infantería de la Academia de Toledo ${ }^{44}$. En ese centro de enseñanza, le sorprende la Guerra Civil, pasando a ser uno de los defensores del Alcázar de Toledo ${ }^{45}$. Tras la liberación de la histórica fortaleza, Milans del Bosch fue destinado a la Legión ${ }^{46}$, permaneciendo en esta unidad el resto del conflicto, donde combatió brillantemente, ganando la Medalla Militar Individual (MMI) ${ }^{47}$.

Finalizada la Guerra Civil, y tras acabar sus estudios militares, se presentó voluntario para la Campaña de Rusia que se inició en 1941, recibiendo el mando de la 9. ${ }^{a}$ compañía de Infantería, perteneciente al $3 .^{\circ}$ Batallón del Regimiento n. ${ }^{\circ} 262$ de la División Azul. En la URSS, permaneció hasta 1942, ganando la Cruz de Hierro de $2 .{ }^{a}$ Clase $^{48}$. Tras su vuelta a España, Milans del Bosch pasó por diferentes destinos, en todos los cuáles demostró un enorme carisma y una gran capacidad de mando ${ }^{49}$, a la vez que realizaba los cursos de EM de los tres Ejércitos, siendo uno de los escasos militares que lo tenían ${ }^{50}$ En 1974, ascendió a general de División, recibiendo el mando de la Gran Unidad más poderosa del Ejército español, la División Acorazada (DAC) Brunete n. ${ }^{\circ} 1^{51}$.

Pero a la vez que ascendía en el escalafón, Milans del Bosch, mantuvo relaciones con el entonces príncipe de España, don Juan Carlos de Borbón, y, con su padre, don Juan; ya que siempre fue un monárquico convencido, llegando incluso a ser amigo de políticos de este signo, contrarios al régimen franquista, como Joaquín Satrústegui ${ }^{52}$. Sin embargo,

44 APA. Causa 2/81. Sumario. F 2486. Escalilla del Arma de Infantería. Año 1936. IHCM. Madrid.

45 APA. Causa 2/81. Sumario. F 2487.

46 APA. Causa 2/81. Sumario. F 2489-2499.

47 APA. Causa 2/81. Sumario. Fs. 2500-2501. María Mérida, op. cit., p. 195.

48 Milans del Bosch, destinado en la citada unidad, aparecía en las Escalillas formando parte de la plantilla del Regimiento de Infantería, n. ${ }^{\circ} 1$. Escalilla del Arma de Infantería. Año 1941-1942. IHCM. Madrid.

49 Eduardo Fuentes Gómez de Salazar, El pacto del capó. Testimonio clave de un militar sobre el 23-F, Temas de Hoy, Madrid, p. 27. Ricardo Pardo Zancada, 23-F. La pieza que falta, Plaza \& Janés, Barcelona, 1999, p. 58-62. APA. Testimonio del coronel de Infantería Fernando Puell de la Villa. Madrid, 24 de marzo de 2005.

50 APA. Causa 2/81. F 2503-6. IHCM. Escalilla del Arma de Infanteria. Año 1943-1944.

51 Asciende el 18 de octubre de 1974. IHCM. Escalilla del Arma de Infantería. Año 1974-1975.

52 APA. Causa 2/81. Sumario. F 3256. 
nunca perteneció a la oposición monárquica. Milans del Bosch era un hombre convencido de las bondades del régimen franquista, y un enemigo declarado del liberalismo y la democracia. Este carácter de monárquico franquista, además de fervientemente anticomunista y antiliberal, iba a quedar patente en dos hechos que tuvieron lugar durante su tiempo de mando en la DAC. El primero fue su papel activo en la desarticulación de la UMD, una organización clandestina dentro de las FAS, nacida de la frustración ${ }^{53}$ y que se había formado el 30 de agosto de $1974^{54}$. El segundo, tuvo lugar el 2 de noviembre de 1975. Ese día, recibió la noticia de que don Juan Carlos de Borbón y Borbón, había realizado un viaje relámpago al Sahara Occidental, con objeto de elevar la moral de las tropas allí destacadas. Milans del Bosch, exultante de alegría por el gesto del futuro Jefe de Estado, se trasladó con buena parte de su oficialidad y suboficialidad, al aeropuerto de Barajas (Madrid), para demostrar su apoyo al gesto del príncipe de España ${ }^{55}$.

Dieciocho días después, moría el general Franco. Milans del Bosch como devoto franquista recibió con tristeza la noticia, paliada por la alegría de la sucesión de Juan Carlos de Borbón a título de Rey ${ }^{56}$. Sin embargo, esta alegría se vio rápidamente truncada cuando se inició el proceso de transición a la democracia hacia el que mostró mucho recelo, como demostró tras la legalización del PCE. Tal vez por eso, Gutiérrez Mellado decidió posponer su ascenso a teniente general, prefiriendo a Antonio Ibáñez Freire, un militar de su completa confianza - criterio subjetivo de elección-, aunque por debajo de Milans del Bosch en el escalafón. Este hecho provocó un grave enfrentamiento entre Gutiérrez Mellado y el entonces jefe de la DAC en el que tuvo que intervenir el

53 «Nace entre capitanes y comandantes con más de diez años de ejercicio profesional frustrante por la escasez de medios y las escasas o nulas perspectivas de cambio positivo, en un clima político cerrado interna y exteriormente, que se acentuaba según iba empeorando la salud de quien encarnaba el poder en el régimen». Javier Calderón Fernández y Florentino Ruíz Platero, Algo más que el 23-F, La Esfera de los Libros, Madrid, 2004, p. 323 .

${ }^{54}$ Julio Busquets y Juan Carlos Losada, Ruido de sables. Las conspiraciones militares en la España del siglo XX, Crítica, Barcelona, 2003, p. 109. Milans del Bosch, como jefe de la DAC, fue quien firmó el parte que inició el procesamiento de los miembros de la UMD. Fundación Ortega-Marañón. Madrid. Entrevista al teniente general José María Sáenz de Tejada y Fernández de Bobadilla. 29 de septiembre de 1987.

55 Alfonso Armada Comyn, Al servicio de la Corona, Planeta, Barcelona, 1983, p. 192.

56 Ricardo Pardo Zancada, op. cit., pp. 34-35. 
propio Rey ${ }^{57}$. Finalmente, el 9 de diciembre de 1977, fue ascendido a teniente general y nombrado capitán general de la III Región Militar ${ }^{58}$. No obstante, a pesar de ese ascenso, Milans del Bosch siguió siendo un enemigo de Suárez y de Gutiérrez Mellado ${ }^{59}$, y, por tanto, un candidato muy poco fiable para el puesto de JEME, a pesar de su enorme prestigio, brillante Hoja de Servicios y gran preparación.

El segundo candidato era el teniente general Jesús González del Yerro Martínez; cuya carrera militar era tan brillante como la de Milans del Bosch, aunque ideológica y personalmente fuera muy distinto. Nacido en Burgos el 25 de diciembre de 1916, había ingresado en la Sección de Infantería de la Academia de Toledo, el 1 de febrero de 1936. La guerra civil le sorprendió de vacaciones en El Escorial (Madrid). Inmediatamente, se incorporó a las columnas del general del general de brigada de Infantería Emilio Mola Vidal ${ }^{60}$. De las columnas de Mola pasaría a la Legión, donde ganaría la MMI, por su actuación en el paso del río Ebro, en la noche del 22 al 23 de marzo de $1938^{61}$. Finalizado el conflicto, y tras un breve periodo de guarnición, pasaría ya como capitán, y de forma voluntaria, a la $14 .{ }^{\mathrm{a}}$ Compañía de Antitanques, perteneciente al 3. ${ }^{\circ}$ Batallón del Regimiento 262 de la División Azul - siendo, por tanto, compañero de Milans del Bosch en dicha Unidad-. Su participación en esa campaña, le iba a proporcionar las cruces de Hierro de 1. ${ }^{\mathrm{a}}$ y $2 .{ }^{\mathrm{a}}$ Clase $^{62}$. De la URSS, regresó en 1943, y comenzó su carrera militar como soldado de guarnición, pero a diferencia de Milans del Bosch - que siempre despreció los puestos civiles, y a los militares que los ocupaban-, que combinaría con destinos políticos, ya que el ministro de Justicia, el tradicionalista Antonio María de Oriol, le nombró director general de Prisiones, un cargo de mucha confianza política que ejercería entre 1965 y 1970. Dos años después, el 2 de octubre de 1972, ascendía a general de brigada de Infantería ${ }^{63}$. Con este grado, su único destino fue la dirección

57 «El Rey visitó la base de helicópteros y la División Acorazada Brunete», Informaciones, 1 de febrero de 1977, p. 2. Eduardo Fuentes Gómez de Salazar, op. cit., pp. 37-38. Francisco Medina, Memoria oculta del Ejército, Espasa-Calpe, Madrid, 2004, p. 289.

58 IHCM. Escalillas del Arma de Infantería. Año 1978.

59 Ricardo Pardo Zancada, op. cit., p. 59-60. Javier Fernández López, op. cit., p.154.

${ }^{60}$ APA. Testimonio oral del teniente general Jesús González del Yerro. Madrid, 21 de marzo de 1996.

61 Carlos Iniesta Cano, Memorias y recuerdos, Planeta, Barcelona, 1984, pp. 122-124.

62 APA. Testimonio oral del teniente general Jesús González del Yerro. Madrid, 21 de marzo de 1996.

${ }^{63}$ ICHM. Escalillas del Arma de Infantería. Años 1971-1973. 
de la Escuela de Estado Mayor (EMM ${ }^{64}$. Durante su periodo de mando en ese centro de enseñanza, se produjo la Revolución de los Claveles en Portugal - 25 de abril de 1974-, sobre la que González del Yerro declaró: «El Ejército español no tiene sus fusiles para adornarlos con claveles ni los claveles florecen en la embocadura de un fusil» ${ }^{65}$; demostrando así su rechazo por la postura que había tomado el Ejército portugués.

El 3 de febrero de 1976, ascendió a general de División, y fue nombrado General Jefe de la División de Infantería Mecanizada Guzmán el Bueno, . $^{\circ}$ 2, la segunda Gran Unidad más poderosa tras la DAC, donde permaneció poco tiempo, pasando ese mismo año a la Dirección de Organización y Campaña del EMC ${ }^{66}$. Al año siguiente, fue nombrado $2 .^{\circ}$ JEME - sirviendo a las órdenes de los tenientes generales Vega Rodríguez y de Liniers y Pidal-, y siendo el responsable del duro manifiesto del CSE tras la legalización del $\mathrm{PCE}^{67}$. El 9 de diciembre de

64 ICHM. Escalillas del Arma de Infantería. Años 1974-1976.

65 «Entrevista con el general González del Yerro (Jefe de la Escuela de Estado Mayor)».ABC, 16 de mayo de 1975, p. 125.

66 ICHM. Escalillas del Arma de Infantería. Año 1977.

${ }^{67}$ María Mérida, Memoria oculta del Ejército, Espasa-Calpe, Madrid, 2004, p. 307. El comunicado decía: «En la tarde del pasado día 12 de abril, el Consejo Superior del Ejército, por convocatoria del Ministro del Departamento, y bajo la presidencia del Teniente General Jefe del Estado Mayor del Ejército, por enfermedad de aquél, se reunió a efectos de considerar la legalización del Partido Comunista de España y el procedimiento administrativo seguido al efecto por el Ministerio de la Gobernación, según el cual se mantuvo sin información y marginado al Ministro del Ejército. El Consejo Superior consideró que la legalización del Partido Comunista de España es un hecho consumado que admite disciplinalmente, pero consciente de su responsabilidad y sujeto al mandato de las Leyes expresa la profunda y unánime repulsa del Ejército ante dicha legalización y acto administrativo llevado a efectos unilateralmente, dada la gran trascendencia política de tal decisión. La legalización del Partido Comunista de España por sí misma, y las circunstancias políticas del momento, determinan la profunda preocupación del Consejo Superior, con relación a instancias tan fundamentales cuales son la Unidad de la Patria, el honor y respeto a su Bandera, la solidez y permanencia de la Corona y el prestigio y dignidad de las Fuerzas Armadas. En este orden, el Consejo Superior exige que el Gobierno adopte, con firmeza y energía, todas cuantas disposiciones y medidas sean necesarias para garantizar los principios reseñados. Vinculado a cualquier decisión que se adopte, en defensa de los valores trascendentes ya expuestos, el Ejército se compromete a, con todos los medios a su alcance, cumplir ardorosamente con sus deberes para con la Patria y la Corona. Madrid, 14 de abril de 1977. FÉLIX ALVÁREZ-ARENAS Y PACHECO». APA. Documento cedido por el coronel de Infantería Fernando Puell de la Villa. 
$1978^{68}$, ascendió a teniente general y fue designado capitán general de Canarias $^{69}$.

Hombre muy prestigioso en las FAS, era en esos momentos el teniente general más joven del Ejército, junto a su compañero de promoción Pedro Merry Gordon, capitán general de la II Región Militar, y el colíder del Ejército, junto a Milans del Bosch ${ }^{70}$. Además, su destino como jefe de la EEM y como 2. ${ }^{\circ}$ JEME, además de sus diplomas de EM tanto del Ejército como del Ejército del Aire, lo hacían especialmente idóneo para ocupar el puesto de JEME. Pero, no era un hombre de confianza del Gobierno, ni tampoco del Jefe del Estado, no sólo por su posición contraria al cambio político, sino también por su ideología franquista $a z u l$, no monárquica ${ }^{71}$, lo que le diferenciaba de Milans del Bosch.

La Hoja de Servicios del candidato del Gobierno, el general de División José Gabeiras Montero no podía rivalizar con las de Milans del Bosch y González del Yerro. Nacido el 20 de julio de 1916 en El Ferrol (La Coruña), había ingresado en la Sección de Artillería de la Academia de Artillería e Ingenieros, de Segovia, el 1 de febrero de 1935. Por tanto, era coetáneo de los otros candidatos. Sin embargo, su carrera militar había sido menos brillante que la de éstos, ya que a pesar de haber participado en la Guerra Civil ${ }^{72}$ y en la campaña de la URSS, no había obtenido ni ascensos por méritos de guerra ni condecoraciones importantes. No obstante, a pesar de estas carencias, alcanzó el grado de general de brigada de Artillería, el 7 de agosto de $1973^{73}$, siendo nombrado Jefe de Estudios del Centro Superior de Estudios de la Defensa (CESEDEN) ${ }^{74}$. Su presencia en dicho organismo durante dos años, coincidió con la de otro artillero, el también general de brigada y luego de división Gutié-

68 ICHM. Escalillas del Arma de Infantería. Año 1979.

69 ICHM. Escalillas del Arma de Infantería. Años 1979-1981.

70 El propio teniente general González del Yerro se reconocía como tal. APA. Testimonio oral del teniente general Jesús González del Yerro. Madrid, 21 de marzo de 1996. Por su parte, el futuro JEME, teniente general José María Sáenz de Tejada y Fernández de Bobadilla afirmó que «González del Yerro tenía tanto "tirón" como Milans del Bosch». Fundación Ortega-Marañón. Madrid. Entrevista al teniente general José María Sáenz de Tejada y Fernández de Bobadilla. 29 de septiembre de 1987.

${ }^{71}$ Ricardo Pardo Zancada, op. cit., p. 289.

72 IHCM. Escalillas del Arma de Artillería. Años 1940-1942.

73 IHCM. Escalillas del Arma de Artillería. Años 1971-1974.

74 IHCM. Escalillas del Arma de Artillería. Año 1975. 
rrez Mellado, con él que iba a tejer una solida amistad, que sería determinante en su carrera militar. En 1975, fue agregado al EMC, donde volvería a coincidir con Gutiérrez Mellado, y donde permaneció hasta su ascenso a general de división, el 22 de septiembre de $1976^{75}$. Con este empleo, y tras permanecer unos meses en situación de «disponible», fue nombrado - de nuevo por Gutiérrez Mellado- secretario general de Asuntos de Política de Defensa. En este cargo se encontraba en mayo de $1979^{76}$. Por tanto, Gabeiras no tenía ni el prestigio militar ni el carisma ni el empleo - teniente general - de Milans del Bosch y González del Yerro, pero tenía la amistad y la confianza del hombre que iba a decidir quien sería el próximo JEME: Gutiérrez Mellado.

\section{La designación del teniente general Jose Gabeiras como Jefe del Estado Mayor del Ejército}

El 16 de mayo de 1979, se reunió el CSE ${ }^{77}$, para elaborar la preceptiva terna, de donde teóricamente el Gobierno debería elegir al futuro JEME. La reunión fue borrascosa dada la situación que se vivía entonces en España ${ }^{78}$ y la pésima relación que existía entre el Gobierno y la cúpula militar. De hecho, Gutiérrez Mellado reconoció posteriormente que en ese CSE, todos

75 IHCM. Escalillas del Arma de Artillería. Años 1976-1977.

76 IHCM. Escalillas del Arma de Artillería. Años 1978.

77 Los tenientes generales asistentes al Consejo Superior del Ejército fueron: JEME, Tomás de Liniers y Pidal; capitán general de la I Región Militar, Guillermo Quintana Lacaci; capitán general de la II Región Militar, Pedro Merry Gordon; capitán general de la III Región Militar, Jaime Milans del Bosch; capitán general de la IV Región Militar, Antonio Ibáñez Freire; capitán general de la V Región Militar, Antonio Elícegui Prieto; capitán general de la VI Región Militar, Fernando Sanjurjo de Caricarte; capitán general de la VII Región Militar, Ángel Campano López; capitán general de la VIII Región Militar, Manuel Fernández Posse; capitán general de la IX Región Militar, Antonio Balcarzar Rubio de la Torre; capitán general de Baleares, Manuel de la Torre Pascual; capitán general de Canarias, Jesús González del Yerro; Ex Jefes del EMC o EME, en Situación B: Emilio Villaescusa Quiles, José Vega Rodríguez y Ramón Cuadra Medina.

78 A la crisis económica que se había iniciado en 1973, se añadía el aumento de la escalada terrorista que tuvo en 1979 su momento culminante, el inició del golpismo que había tenido en la Operación Galaxia del año anterior su primera manifestación, y el comienzo de la crisis del partido gobernante, la Unión de Centro Democrático (UCD), con sus derrotas en las elecciones autonómicas vascas y catalanas. Véase «El PNV podría formar un Gobierno monocolor», $A B C, 11$ de marzo de 1980, p. 1 y «Jordi Pujol: "Buena armonía con el resto de España”». $A B C, 22$ de marzo de 1980, p. 1. 
los presentes «eran sus enemigos» ${ }^{79}$. Según el entonces general de brigada de Artillería José María Sáenz de Tejada y Fernández de Bobadilla - Jefe del EM de la I Región Militar-, que recibió información de lo ocurrido en la reunión por dos asistentes - el teniente general Guillermo Quintana Lacaci, capitán general de la I Región Militar, y su íntimo amigo, Milans del Bosch-, esta situación de tensión llevó a todos los presentes a optar por un criterio muy militar para elegir su candidato para el puesto de JEME: el de antigüedad. Así pidieron en bloque al más antiguo de los tenientes generales en activo, Ángel Campano López - capitán general de la VII Región Militar (Valladolid), MMI, antiguo alférez provisional, veterinario, de ideología franquista $a z u l$, y contrario al proceso de cambio político- que aceptase el cargo ${ }^{80}$. Sin embargo, Campano - que según otro militar contrario al proceso de cambio político e implicado posteriormente en el golpe de Estado del 23-F, el general de división Luis Torres Rojas, «se había dormido en los laureles» ${ }^{81}-$, se negó, argumentando su avanzada edad -era más joven que Milans del Bosch ${ }^{82}-$ y su salud precaria. La negativa de Campano abrió las puertas a las candidaturas de Milans del Bosch y de González del Yerro. Sin embargo, ninguno de los dos, según Sáenz de Tejada, obtuvo una mayoría clara, aunque Milans del Bosch llevaba cierta ventaja en votos, estando apoyado por los tenientes generales que durante el golpe de Estado del 23-F se mostraron más favorables a intervenir. Lo que significa que fue apoyado por el propio Campano, Merry Gordon, Antonio Elícegui Prieto - capitán general de la V Región militar (Zaragoza) - y Manuel de la Torres Pascual - capitán general de Baleares- ${ }^{83}$. A González del Yerro

${ }^{79}$ Fundación Ortega-Marañón. Madrid. Entrevista al capitán general honorario Manuel Gutiérrez Mellado. 8 de septiembre de 1987.

80 Fundación Ortega-Marañón. Madrid. Entrevista al teniente general José María Sáenz de Tejada y Fernández de Bobadilla. 29 de septiembre de 1987.

81 APA. Testimonio oral del general de División Luís Torres Rojas. Madrid, 4 de junio de 1998.

${ }^{82}$ Había nacido el 3 de septiembre de 1915. IHCM. Escalillas del Arma de Infantería. Año 1942.

${ }^{83}$ Fundación Ortega-Marañón. Madrid. Entrevista al teniente general José María Sáenz de Tejada y Fernández de Bobadilla. 29 de septiembre de 1987. Existen tres testimonios que corroboran que esos cuatro tenientes generales fueron los que apoyaron a Milans del Bosch durante el 23-F. El primero es el de Quintana Lacaci, que elaboró un documento durante el golpe de Estado del 23-F, donde se puede leer: «1. ' (Quintana) Legal. Lealtad al Rey. 2. ${ }^{\text {a }}$ (Merry Gordon) Gracias a Urrutia. Esperando a los demás para unirse. 3. ${ }^{\text {a }}$ (Mi-

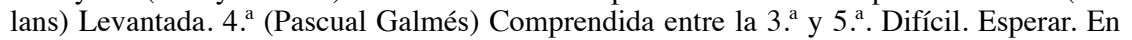
el fondo legal, pero si 5. se une, 4. ${ }^{a}$ también. 5. . (Elícegui) No hizo más que llamarme para 
le apoyaron, entre otros, su amigo Quintana Lacaci - compañero de promoción-, y Vega y Liniers, a cuyas órdenes había servido ${ }^{84}$. Esta división provocó que CSE no pudiera presentar un candidato destacado ${ }^{85}$; entregando al ministro de Defensa una terna formaban, además de por Milans del Bosch y González del Yerro, por Elícegui Prieto, amigo de Milans del Bosch y el n. ${ }^{\circ}$ 1 de la promoción de González del Yerro ${ }^{86}$.

Una vez entregada la terna, se daba por segura la elección de Milans del Bosch, dada su ventaja de votos sobre González del Yerro, pero al día siguiente Diario 16 - dada las informaciones tan fiables que tenía en el ámbito de las FAS - anunció que podría haber sorpresas en la elección del nuevo JEME ${ }^{87}$. Y las hubo.

El día 19, se conocía el nombre del nuevo JEME: el recién ascendido teniente general José Gabeiras Montero. La decisión se tomó durante el Consejo de Ministros del día 18, viernes; pues, era a este organismo a quien le correspondía decidir sobre la propuesta que le hiciera el vicepresidente del Gobierno para Asuntos de la Defensa. Gutiérrez Mellado no confiaba en ninguno de los tres tenientes generales que formaban la terna,

ver que iba a hacer yo, pues "algo habría que hacer". 6. (Polanco) Completamente legal y leal al Rey. 7. (Campano) Con muchas dudas, pues según él "algo habría que hacer que la Alerta 2". 8. " (Fernández Posse) En el fondo, legal. Si la 6. ${ }^{a}$ se une, también lo haría. 9. ${ }^{a}$ (Delgado) Completamente leal. Baleares (De la Torre) Esperando a ver que pasaba, se uniría a Milans. Canarias (González del Yerro) Dudas. Al enterarse del protagonismo de Milans y de que Armada quería ser presidente del Gobierno, se muestra leal. Pregunta por qué Armada y no otro militar (se refiere a él) en una conversación conmigo». «Militares golpistas planearon matar al rey durante un desfile en La Coruña en 1985», El País, 17 de febrero de 1991, pp. 1-4. El segundo, el de Armada, que hace referencia a Merry Gordon, Elícegui, Campano y De La Torre como los principales apoyos de Milans del Bosch durante el 23-F. José Manuel Cuenca Toribio, Conversaciones con Alfonso Armada, Actas, Madrid, 2001, p. 89-91. Y el tercero el del propio Milans del Bosch. APA. Causa 2/81. Acta de la celebración del Consejo. F 37.

${ }^{84}$ El teniente general González del Yerro reconoce que esos eran sus principales amigos en el CSE. APA. Testimonio oral del teniente general Jesús González del Yerro. Madrid, 21 de marzo de 1996.

${ }^{85}$ Así lo reconoce el futuro JEME Sáenz de Tejada. Fundación Ortega-Marañón. Madrid. Entrevista al teniente general José María Sáenz de Tejada y Fernández de Bobadilla. 29 de septiembre de 1987. Por su parte, Gutiérrez Mellado dice que no hubo terna. Fundación Ortega-Marañón. Madrid. Entrevista al capitán general honorario Manuel Gutiérrez Mellado. 8 de septiembre de 1987.

${ }^{86}$ APA. Testimonio oral del teniente general Jesús González del Yerro. Madrid, 21 de marzo de 1996.

87 «Liniers cesa como Jefe del Estado Mayor del Ejército», Diario 16, 17 de mayo de 1979 , p. 2. 
por eso decidió optar por su amigo ${ }^{88}$. Es decir, se inclinó de nuevo por criterios subjetivos - confianza política - , y no objetivos - antigüedad u Hoja de Servicios - a la hora de cubrir una vacante importante. No obstante, él siempre consideró que el nombramiento era absolutamente legal y legítimo, cosa indudable ${ }^{89}$, y que había elegido a Gabeiras porque «estaba muy bien preparado ${ }^{90}$.

Por su parte, Gabeiras afirmó que su elección fue obra del ministro de Defensa, Rodríguez Sahagún, y no de Gutierrez Mellado. Según su propio testimonio, días antes del cese por edad de Liniers, y dado el puesto que ocupaba en el Ministerio de Defensa, Rodríguez Sahagún le pidió una lista con todos los posibles candidatos para el cargo de JEME, en la que se encontraba el propio Gabeiras; añadiendo que también le entregase informes confidenciales sobre algunos de esos candidatos, a lo que el general se negó de forma enérgica, diciéndole que los expedientes militares de los mismos estaban a disposición del ministro por si quería consultarlos. Tras la reunión del CSE y al no haber un candidato claro, Rodríguez Sahagún decidió nombrar al JEME directamente, y acordándose de la sinceridad que había tenido con él, optó por su persona ${ }^{91}$. Sin embargo, esta versión de los hechos no se corresponde con la realidad, ya que quien realmente

${ }^{88}$ Real Decreto 1165/1979, de 18 de mayo, por el que se nombra Jefe del Estado Mayor del Ejército al General de División del Ejército de Tierra don José Gabeiras Montero, promoviéndole al empleo de Teniente General del Ejército .de Tierra. BOE, 19 de mayo de 1979.

89 Manuel Gutiérrez Mellado, Un soldado de España, Argos Vergara, Barcelona, 1983, p. 95. De acuerdo con la Ley 15/1973, de 19 de diciembre (BOE, 20 de diciembre de 1973), que había modificado la ya citada Ley 12/1961, de 19 de abril (BOE, 22 de abril de 1961), el art. 14 establecía: «El ascenso a la categoría de General de División o asimilado y a la de Teniente General, se otorgará por Decreto entre los del empleo inferior inmediato respectivo que se encuentren en el primer tercio de la Escala, hayan cumplido el tiempo mínimo de efectividad de destino y mando que se determina en el artículo quinto de la presente Ley y sean incluidos en los cuadros de elección por el Consejo Superior del Ejército, en atención a las circunstancias de todo orden que concurran en ellos». Gabeiras se encontraba en ese tercio, y llevaba dos años como general de división, efectividad exigida por el art. 5 de la Ley 12/1961; por tanto su ascenso era legal. Igualmente, el Real Decreto 3026/1976, de 23 de diciembre, por el que se regulan las atribuciones, funciones y responsabilidades del Jefe del Estado Mayor del Ejército, establecía en su art. 10: «En caso de recaer la elección en un general de división, ascenderá automáticamente a teniente general». Esa fue la situación en la que se encontraba Gabeiras. Por tanto, su elección se ajustó también a la legalidad de acuerdo con esta otra norma.

${ }^{90}$ Fundación Ortega-Marañón. Madrid. Entrevista al capitán general honorario Manuel Gutiérrez Mellado. 8 de septiembre de 1987.

${ }^{91}$ Fundación Ortega-Marañón. Madrid. Entrevista al teniente general José Gabeiras Montero. 11 de diciembre de 1987. 
nombró al nuevo JEME fue Gutiérrez Mellado, como hemos demostrado. Pero además el vicepresidente del Gobierno tomó otra decisión muy importante: ascender a los cinco generales de división que estaban por delante de Gabeiras en el escalafón - Luis Álvarez Rodríguez, José Morcillo Garcerán, Ricardo Arozarena Girón, Antonio Pascual Galmes y Pedro Fontela Fernández $z^{92}$ - , para evitar cualquier sensación de agravio hacia ellos.

Ambas decisiones fueron muy mal recibidas en los sectores franquistas tanto civiles como militares. Así, el diputado del Frente Nacional, Blas Piñar, interpeló al ministro de Defensa en el Congreso de los Diputados acusándoles de haber tomado una decisión «arbitraria» y que suponía un «desaire» para todos los generales que precedían a Gabeiras en el escalafón; a lo que Rodríguez Sahagún contestó que todos los ascensos y nombramientos eran «legales» ${ }^{93}$. En el seno del Ejército, si la elección de Gabeiras fue muy mal recibida ${ }^{94}$, dado su escaso prestigio y su empleo; el ascenso de seis generales de división al empleo superior de una sola vez, fue considerada escandalosa, hasta el extremo de que jocosamente comenzaron a ser conocidos como los «generales del Palmar de Troya», por la analogía con la forma en la que el Papa Clemente ordenaba «obispos» y «cardenales» en ese lugar ${ }^{95}$.

El descontento de la cúpula del Ejército con la decisión del Gobierno, y más concretamente de Gutiérrez Mellado, se manifestaría en el primer CSE que presidió Gabeiras, y que el relató de la siguiente manera ${ }^{96}$ :

92 Estos ascensos aparecieron en los reales decretos 1145, 1161, 1162, 116, 1164 respectivamente. BOE, 19 de mayo de 1979.

93 «Todos los ascensos son legales». ABC, 21 de mayo de 1979, pp. 1 y 7.

94 Peor les sentó a los principales aspirantes al puesto: González del Yerro y Milans del Bosch. El primero, años después, todavía recordaba el episodio con cierta amargura, afirmando, sobre la decisión de Gutiérrez Mellado, que «esas no son formas». APA. Testimonio oral del teniente general Jesús González del Yerro. Madrid, 21 de marzo de 1996. Mientras que el segundo, tuvo una respuesta inmediata para la decisión de Gutiérrez Mellado. Diez días después de este hecho, tuvo lugar el juicio contra el general de brigada de Infantería Juan Atarés Peña, jefe de la III Zona de la Guardia Civil, que el 17 de noviembre de 1978, en el Arsenal Militar de Cartagena (Murcia), había insultado a Gutiérrez Mellado. Atarés fue absuelto, y Milans del Bosch declaró: «Creo que ha sido una sentencia justa del Consejo de Guerra, por eso la ratifiqué ¿La impresión que me produjo?, pues la misma que ha debido producir en todo buen compañero que conozca las virtudes humanas y militares del general Atarés». María Mérida, op. cit., p. 209.

95 Ricardo Pardo Zancada, op. cit., p. 74.

96 Francisco Medina, op . cit., p. 343-344. Una versión muy similar de los hechos dio en la entrevista grabada realizada para la Fundación Ortega-Marañón. Fundación Ortega-Marañón. Madrid. Entrevista al teniente general José Gabeiras Montero. 11 de diciembre de 1987. 
En fin, el primer Consejo Superior del Ejército..., eso fue..., yo no sé lo que habrá pasado don Juan de Austria en la batalla de Lepanto, ni lo que habrá pasado Napoleón en Waterloo, pero yo creo que ninguno de los dos tuvo un enemigo tan numeroso ni tan próximo como yo durante el primer Consejo Superior del Ejército. Aquel Consejo se caracterizó porque ¡hablaron todos! (...). Ahora, enemigos, enemigos, eran Campano, Vega, Milans del Bosch..., y el de Canarias, González del Yerro... Milans de palabra apenas se expreso. Se expresó con gestos sobre lo que iban haciendo los demás. Él era incapaz de dar la cara, en absoluto. Hacía gestos de reproche o aprobación sobre lo que decían los demás. Decirme a mí..., nada. ¿Quiénes fueron los más duros? El más duro fue Vega. Campano fue opuesto, pero no fue duro. Pero González del Yerro y Vega, esos si fueron... ¿Qué si Vega llegó al insulto... que si fue a él al que tuve que decirle que se saliera si no rectificaba? No, no fue exactamente insulto; fue grosería en las expresiones. En fin, entonces cuando terminaron todos yo inicié mi discurso con la siguiente observación: «en este Consejo fuera de los tres oficiales provenientes de la Academia Militar de Zaragoza, que ya no están en activo, yo soy el de mayor antigüedad en el servicio de todos los aquí presentes. En cuanto a meritos de paz, no pongo a ninguno por delante de mí. A lo sumo, lo pongo al mismo nivel. Y en cuanto a méritos de guerra, sólo pongo por delante de mí a los dos medallas militares que están aquí presentes. A los demás los pongo detrás de mí o a mi nivel. He escuchado con toda paciencia lo que me habéis dicho, y he oído frases que quiero pensar que no las he escuchado, o interpretado bien, así es que termino y resumo esto en esta pregunta: ¿mi nombramiento es legal o ilegal?» Bajaron la cabeza todos y dijeron que era legal. No les gustaba, pero no podían decir que era ilegal. Al día siguiente el capitán general de Madrid, Guillermo Quintana, despachaba con el Rey, como hacía todos los miércoles. Y el Rey le preguntó a Guillermo Quintana..., porque, claro, la preocupación llegaba hasta arriba: «¿Qué tal Gabeiras en el Consejo de ayer?». Y le contestó: «Señor, las dos orejas y el rabo». Ese fue el comentario que hizo.

Este testimonio es importante por dos aspectos. El primero porque demuestra que la política de ascensos de Gutiérrez Mellado había conseguido su objetivo: romper la unidad corporativa del Ejército, impidiéndole actuar con una sola voz frente a las decisiones del Gobierno. Y la segunda porque crea la sensación de que Gabeiras se hizo con el control del CSE desde su primera comparecencia en el mismo. Si bien el primer aspecto es indiscutible; el segundo no se ajusta a la realidad. Pues, a pesar de que ser calificado como un hombre muy soberbio y con maneras «chulescas», por 
militares nada sospechosos de simpatías involucionistas ${ }^{97}$; Gabeiras era - según otro militar muy amigo y colaborador de Gutiérrez Mellado- un hombre muy blando y con un cierto complejo de inferioridad ${ }^{98}$. Un JEME al que desde el primer momento despreciaron tanto González del Yerro como especialmente Milans del Bosch, quien se negó a quedarse al almuerzo que se celebraba tras cada $\operatorname{CSE}^{99}$ y a ponerse al teléfono cuando Gabeiras le llamaba ${ }^{100}$.

\section{Conclusión}

La elección de Gabeiras como JEME demostró dos cosas. La primera, que las relaciones entre el Gobierno y la cúpula del Ejército estaban completamente rotas, y esa ruptura se manifestaba en el hecho de que el poder ejecutivo no confiaba en la casi totalidad los tenientes generales. La única excepción podría ser la de Quintana Lacaci ${ }^{101}$. La segunda, que a pesar de esa tensión existentes, el Gobierno volvió a imponer su criterio sobre la cúpula militar, lo que ya había hecho con la legalización del PCE; demostrando así que el poder civil se estaba imponiendo definitivamente sobre el militar.

Pero, más allá de las tensiones que ocasionó y de las propias limitaciones tanto personales como profesionales del nuevo JEME, ¿fue posi-

97 «La actitud del general Gabeiras fue también foco de tensiones, ya que su forma de ser era propensa a ello. Definir su porte como de muy altivo, chulesco para algunos, no es ninguna exageración». Fernández López, op. cit., p. 147. Javier Fernández López es coronel de Ingenieros.

98 Testimonio del teniente general Javier Calderón Fernández. Medina, op. cit., p. 344

99 Armada, op. cit., p. 215.

100 Medina, op . cit., p. 344. El entonces general de división Alfonso Armada Comyn,

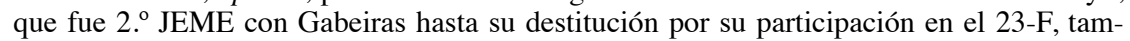
bién reconoce el enfrentamiento entre éste y Milans del Bosch. Armada, op. cit., p. 215. El futuro JEME Sáenz de Tejada reconoce que Gabeiras no tenía prestigio para ser JEME. Fundación Ortega-Marañón. Madrid. Entrevista al teniente general José María Sáenz de Tejada y Fernández de Bobadilla. 29 de septiembre de 1987.

101 Quintana Lacaci, antiguo Coronel Jefe del Regimiento de Guardia de Franco, y hombre de la máxima confianza del anterior Jefe de Estado, que le ascendió a general, sin ser DEM - condición que se consideraba sine qua non para llegar al generalato - fue un militar que se adaptó completamente al cambio político, siendo totalmente leal a Gutiérrez Mellado y el principal apoyo de Gabeiras en el CSE. Javier Fernández López, op . cit., pp. 224-225 
tiva la elección de Gabeiras? Si, y eso se demostró durante el golpe de Estado del 23-F. Es cierto que el JEME no fue clave en su desarticulación. Ya que, por un lado, fue punteado - como también lo fue el Rey - por los capitanes generales ${ }^{102}$. Y, por otro, en la noche del 23 al 24 de febrero, autorizó a Armada - siguiendo órdenes de la Superioridad - a trasladarse al Congreso de los Diputados y proponerse como presidente del Gobierno «a título personal» ${ }^{103}$. Pero también es cierto que durante el golpe de Estado, el alto mando del Ejército careció de unidad, dividiéndose entre los capitanes generales partidarios de apoyar a Milans del Bosch y los contrarios a hacerlo, sin que se llegara a consensuar una postura común, por la carencia de un liderazgo claro en el Ejército. Fue esa falta de unidad, producto de la ausencia de un líder, la que a la postre provocó la pasividad de todos los mandos regionales, y en consecuencia, la salvación del sistema democrático ${ }^{104}$.

Por el contrario, si el JEME, en vez de ser Gabeiras, hubiese sido Milans del Bosch o González del Yerro - dos militares de mentalidad involucionista ${ }^{105}$ - , la situación habría sido muy diferente, ya que ese líder militar que los sectores golpistas del Ejército necesitaban para intervenir en apoyo de los conjurados del 23-F hubiese existido; lo que habría podido asegurar el éxito del golpe de Estado.

Por tanto, la elección de Gabeiras impidió crear ese líder militar, y fue por tanto un acierto más, tal vez uno de los más importantes, dentro del proceso de reforma militar que había iniciado el capitán general honorario Manuel Gutiérrez Mellado.

102 José Manuel Cuenca Toribio, op. cit., pp. 139-140.

103 Roberto Muñoz Bolaños, Operación Turia. La III Región Militar durante el 23-F, Punto de Vista, Madrid, 2014, pp. 34-35.

104 El documento de Quintana Lacaci citado en la nota 79 es la muestra más palpable de esa división, y que no se consensuara una posición común entre los capitanes generales.

105 Esa mentalidad queda patente en la participación de Milans del Bosch en el golpe de Estado del 23-F, y en todos los movimientos que González del Yerro desarrolló durante la segunda mitad de 1980 y durante todo 1981, con objeto de organizar un Gobierno de concentración nacional, con el apoyo del democristiano conservador Alfonso Osorio, teniendo por tanto el mismo objetivo que Armada en el golpe de Estado del 23-F. Sobre los movimientos políticos de González del Yerro, véase Off the record, 7, 9 y 17 de octubre de 1980, Alfonso Osorio, De orilla a orilla, De orilla a orilla, Plaza \& Janés, Barcelona, 2000, p. 385, Miguel Platón, Hablan los militares, Planeta, Barcelona, 2001, p. 569. 